\title{
A model for the rat exploratory behavior in the elevated plus-maze Julián Tejada1 ${ }^{1}$, Rodrigo Oliveira ${ }^{2}$, Cristiane Salum ${ }^{3}$, Sílvio Morato ${ }^{1}$ and Antonio Roque*4
}

\author{
Address: ${ }^{1}$ Department of Psychology and Education, School of Philosophy, Sciences and Letters of Ribeirão Preto, University of São Paulo, $14040-$ \\ 901 Ribeirão Preto, SP, Brazil, ${ }^{2}$ Computational and Experimental Neuroplasticity Laboratory, Krasnow Institute, George Mason University, \\ Rockfish Creek Lane, Fairfax, VA 22030-4444, USA, ${ }^{3}$ Department of Morphology, Stomatology and Physiology, School of Odontology of Ribeirão \\ Preto, University of São Paulo, 14040-901 Ribeirão Preto, SP, Brazil and ${ }^{4}$ Department of Physics and Mathematics, School of Philosophy, Sciences \\ and Letters of Ribeirão Preto, University of São Paulo, 14040-901 Ribeirão Preto, SP, Brazil \\ Email: Antonio Roque* - antonior@neuron.ffclrp.usp.br \\ * Corresponding author
}

from Sixteenth Annual Computational Neuroscience Meeting: CNS*2007

Toronto, Canada. 7-12 July 2007

Published: 6 July 2007

BMC Neuroscience 2007, 8(Suppl 2):P37 doi:10.1 I86//47|-2202-8-S2-P37

C 2007 Tejada et al; licensee BioMed Central Ltd.

\section{Background}

The elevated plus-maze (EPM) is a standard animal model of fear/anxiety in which the rodent is initially placed at the center of an elevated four-arm maze in which two arms are open and two are enclosed by walls. The anxietyrelated behavior comes from the conflict between staying in a safe place (the enclosed arms) and exploring a potentially dangerous environment (the open arms). The rat's anxiety level in the EPM is characterized by two main measures, namely the number of times the animal enters each kind of arm and the time spent in each kind of arm. In this work we present a modified version of an earlier model [1] for rat exploratory behavior based on competition between motivation and aversion and compare the simulation results with experimental data for real rats [2].

\section{Methods}

The model is a network based on the structure of a plusmaze divided into squares of equal size, five per arm and a central one [1]. Each network unit corresponds to a specific square and the connections, only between closest neighbors, represent the possible adjacent squares where a virtual rat could go. The exploratory behavior is modeled by a matrix of network weights $w_{i j}$ whose elements represent the rat's tendency for exploring square $i$ from square $j$. This matrix is given by $w_{i j}=M_{i j}-A_{i j}$, where $M_{i j}$ is the animal's motivation to explore square $i$ from square $j$ and $A_{i j}$ is its aversion to move to square $i$ from square $j$. This equation was kept from the original model but here the equations that model the way the matrices $M_{i j}$ and $A_{i j}$ depend on he number of times $N_{i j}$ the virtual rat moves from square $j$ to square $i$ were modified to $M_{i j}=M /(\mu+$ $\left.N_{i j}{ }^{\beta i}\right)$ and $A_{i j}=A /\left(v+N_{i j}{ }^{\alpha i}\right)$, where $M$ and $A$ are constants which have the same values for all virtual rats and determine, respectively, the initial values of motivation and anxiety, $\mu$ and $v$ are parameters that vary from virtual rat to virtual rat determining their individual differences and $\alpha i$ and $\beta i$ are positive exponents which determine how motivation and anxiety respectively decay with $N_{i j}$. The exponent $\alpha i$ can have two different values, one when square $i$ represents a place inside an open arm, which we will call $\alpha i o$, and the other when $i$ represents any other square of the EPM, which we will call cia. The exponent $\beta i$ also can have two different values, one when square $i$ represents a place inside a closed arm, which we will call $\beta i c$, and the other when $i$ represents any other place of the EPM, which we will call $\beta i a$. The values of the parameters were determined by an exhaustive search using genetic algorithms with a fitness function which combines the two anxiety measures mentioned above.

\section{Results}

The results of the simulations agree well with experimental data from our lab [2]. The time spent in the arms and 
the number of entries into them by the virtual rat are similar to the same measures exhibited by real rats.

\section{Conclusion}

The modified model is capable of replicating the rat exploratory behavior in the EPM. The major weakness of the model is its large number of parameters, which turns its interpretation in a biological or cognitive context difficult. In spite of this, the model can be considered as a first step for a theoretical understanding of the basis of rodent exploratory behavior.

\section{Acknowledgements}

We would like to thank FAPESP for funding this work.

\section{References}

I. Salum C, Morato S, Roque AC: Anxiety-like behavior in rats: a computational model. Neural Networks 2000, 13:2I-29.

2. Salum C, Roque-da-Silva AC, Morato S: Conflict as a determinant of rat behavior in three types of elevated plus-maze. Behav Processes 2003, 63:87-93.

Publish with Biomed Central and every scientist can read your work free of charge

"BioMed Central will be the most significant development for disseminating the results of biomedical research in our lifetime. "

Sir Paul Nurse, Cancer Research UK

Your research papers will be:

- available free of charge to the entire biomedical community

- peer reviewed and published immediately upon acceptance

- cited in PubMed and archived on PubMed Central

- yours - you keep the copyright

Submit your manuscript here:

http://www.biomedcentral.com/info/publishing_adv.asp 